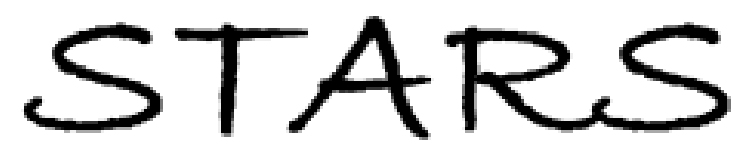

University of Central Florida

STARS

$1-1-2006$

\title{
Carrier concentration dependence of acceptor activation energy in p-type ZnO
}

\author{
O. Lopatiuk-Tirpak \\ University of Central Florida
}

W. V. Schoenfeld

University of Central Florida

L. Chernyak

University of Central Florida

F. X. Xiu

J. L. Liu

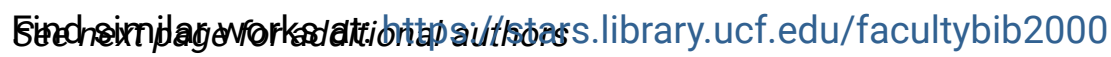

University of Central Florida Libraries http://library.ucf.edu

This Article is brought to you for free and open access by the Faculty Bibliography at STARS. It has been accepted for inclusion in Faculty Bibliography 2000s by an authorized administrator of STARS. For more information, please contactSTARS@ucf.edu.

\section{Recommended Citation}

Lopatiuk-Tirpak, O.; Schoenfeld, W. V.; Chernyak, L.; Xiu, F. X.; Liu, J. L.; Jang, S.; Ren, F.; Pearton, S. J.; Osinsky, A.; and Chow, P., "Carrier concentration dependence of acceptor activation energy in p-type ZnO" (2006). Faculty Bibliography 2000s. 6377.

https://stars.library.ucf.edu/facultybib2000/6377

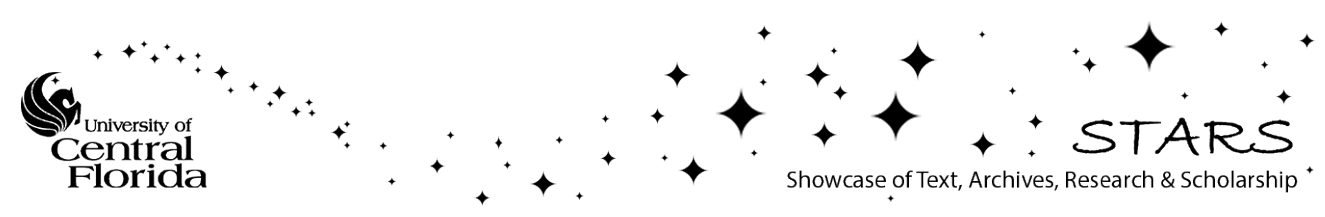


Authors

O. Lopatiuk-Tirpak, W. V. Schoenfeld, L. Chernyak, F. X. Xiu, J. L. Liu, S. Jang, F. Ren, S. J. Pearton, A. Osinsky, and P. Chow

This article is available at STARS: https://stars.library.ucf.edu/facultybib2000/6377 


\section{Carrier concentration dependence of acceptor activation energy in $p$-type ZnO}

Cite as: Appl. Phys. Lett. 88, 202110 (2006); https://doi.org/10.1063/1.2206700

Submitted: 06 January 2006 . Accepted: 27 April 2006 . Published Online: 18 May 2006

O. Lopatiuk-Tirpak, W. V. Schoenfeld, L. Chernyak, F. X. Xiu, J. L. Liu, S. Jang, F. Ren, S. J. Pearton, A. Osinsky, and P. Chow

\section{ARTICLES YOU MAY BE INTERESTED IN}

A comprehensive review of $\mathrm{ZnO}$ materials and devices

Journal of Applied Physics 98, 041301 (2005); https://doi.org/10.1063/1.1992666

Carrier concentration and activation energy in heavily donor-doped silicon Journal of Applied Physics 61, 591 (1987); https://doi.org/10.1063/1.338210

Oxygen vacancies in $\mathrm{ZnO}$

Applied Physics Letters 87, 122102 (2005); https://doi.org/10.1063/1.2053360
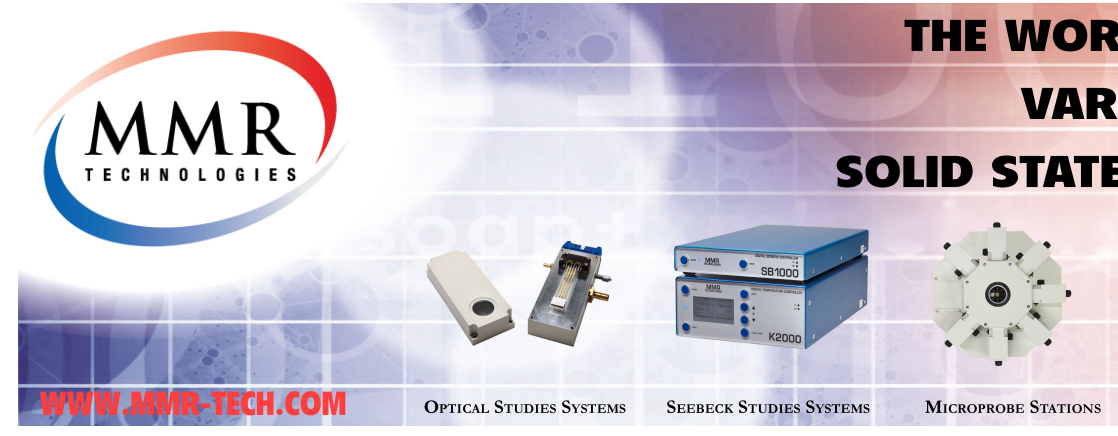

THE WORLD'S RESOURCE FOR VARIABLE TEMPERATURE 


\title{
Carrier concentration dependence of acceptor activation energy in p-type $\mathrm{ZnO}$
}

\author{
O. Lopatiuk-Tirpak, W. V. Schoenfeld, and L. Chernyak ${ }^{\text {a) }}$ \\ University of Central Florida, Orlando, Florida 32816-2385 \\ F. X. Xiu and J. L. Liu \\ Department of Electrical Engineering, University of California, Riverside, California 92521 \\ S. Jang, F. Ren, and S. J. Pearton \\ Department of Materials Science and Engineering, University of Florida, Gainesville, Florida 32611
}

A. Osinsky and P. Chow

SVT Associates, Eden Prairie, Minnesota 55344

(Received 6 January 2006; accepted 27 April 2006; published online 18 May 2006)

The characteristics of an acceptor level in Sb-doped, p-type $\mathrm{ZnO}$ were studied using cathodoluminescence (CL) spectroscopy as a function of hole concentration. Variable-temperature CL measurements allowed us to estimate the activation energy of an Sb-related acceptor from temperature-induced decay of CL intensity. The values of activation energy of about $212 \pm 28$, $175 \pm 20,158 \pm 22$, and $135 \pm 15 \mathrm{meV}$ were obtained for samples with carrier concentrations of $1.3 \times 10^{17}, 6.0 \times 10^{17}, 8.2 \times 10^{17}$, and $1.3 \times 10^{18} \mathrm{~cm}^{-3}$, respectively. The involvement of acceptor levels is supported by the temperature-dependent hole concentration measurements. The possible origins of the strong temperature dependence are discussed. (C) 2006 American Institute of Physics.

[DOI: 10.1063/1.2206700]

Although nitrogen has long been considered the substitutional acceptor of choice for obtaining $p$-type conductivity in $\mathrm{ZnO}$, the possibility of $p$-type doping with larger radii group $\mathrm{V}$ atoms, such as phosphorus, ${ }^{1-3}$ arsenic, ${ }^{4,5}$ and antimony, ${ }^{6,7}$ has also been explored. The studies demonstrated that despite the large size mismatch, which, in principle, should inhibit the substitution of these impurities on the oxygen site, effective $p$-type doping with hole concentrations up to $10^{20} \mathrm{~cm}^{-3}$ can be achieved. ${ }^{7}$ These findings prompted the first-principles investigation by Limpijumnong et al., who suggested that the role of acceptors in sizemismatched impurity doped $\mathrm{ZnO}$ is performed by a complex of the impurity with two zinc vacancies $\left(X_{\mathrm{Zn}}-2 \mathrm{~V}_{\mathrm{Zn}}\right.$, where $X$ denotes As or $\mathrm{Sb}$ ), the ionization energy of which is severalfold lower than that of a substitutional configuration and is consistent with the independent experimental observations. ${ }^{8}$ In this letter, we explore the nature of the Sb-related acceptor level by studying the luminescence properties as a function of carrier concentration.

The experiments were performed on $\mathrm{ZnO}: \mathrm{Sb}$ layers grown on $\mathrm{Si}(100)$ substrates by an electron cyclotron resonance (ECR)-assisted molecular beam epitaxy (MBE). The detailed growth procedures are available in Ref. 6. Hall effect measurements revealed a strong $p$-type conductivity, with hole concentrations up to $1.3 \times 10^{18} \mathrm{~cm}^{-3}$ and mobility up to $28.0 \mathrm{~cm}^{2} / \mathrm{V} \mathrm{s}$ at room temperature (Table I).

Cathodoluminescence (CL) measurements were conducted in situ in the Philips XL30 scanning electron microscope (SEM) integrated with Gatan MonoCL cathodoluminescence system. The SEM is also fitted with a hot stage and an external temperature controller (Gatan) allowing for temperature-dependent experiments. The decay of nearband-edge (NBE) luminescence intensity was monitored as a

\footnotetext{
${ }^{a)}$ Electronic mail: chernyak@physics.ucf.edu
}

function of temperature in the range of $25-175^{\circ} \mathrm{C}$. Accelerating voltage of $10 \mathrm{kV}$ was used. Note that each measurement was taken in a previously unexposed area to avoid the potential influence of electron irradiation. ${ }^{9,10}$

The investigation of the luminescence properties of Sbdoped $\mathrm{ZnO}$ was started with the acquisition of roomtemperature cathodoluminescence spectra shown in Fig. 1. The inset of Fig. 1 reveals that the CL spectra of all four samples are dominated by the NBE band, which generally contains the band-to-band transition as well as the transition from the conduction band to a deep, neutral acceptor level $\left(e, A^{0}\right) .{ }^{10,11}$ Since acceptor levels form a band in the forbidden gap, the redshift of the NBE peak with increasing carrier concentration (i.e., higher doping levels) is consistent with the $\left(e, A^{0}\right)$ emission and may indicate the broadening of the Sb-related acceptor band. ${ }^{12,13}$ Another observation that can be made from Fig. 1 is the systematic decay in intensity of the NBE luminescence with increasing doping level. This decrease may be attributed to the reduction in radiative recombination rates as more disorder is introduced into the $\mathrm{ZnO}$ lattice by large-radius $\mathrm{Sb}$ atoms. The increasing trend in the values of the full width at half maximum (FWHM) of the NBE spectra provides further evidence for the impact of the size-mismatched dopant-FWHM values were determined to

TABLE I. Room-temperature electronic properties of Sb-doped $p$-type $\mathrm{ZnO}$ films.

\begin{tabular}{ccc}
\hline \hline Sample No. & $\begin{array}{c}\text { Hole concentration } \\
\left(\mathrm{cm}^{-3}\right)\end{array}$ & $\begin{array}{c}\text { Carrier mobility } \\
\left(\mathrm{cm}^{2} / \mathrm{V} \mathrm{s}\right)\end{array}$ \\
\hline 1 & $1.3 \times 10^{17}$ & 28.0 \\
2 & $6.0 \times 10^{17}$ & 25.9 \\
3 & $8.2 \times 10^{17}$ & 23.3 \\
4 & $1.3 \times 10^{18}$ & 20.0 \\
\hline \hline
\end{tabular}




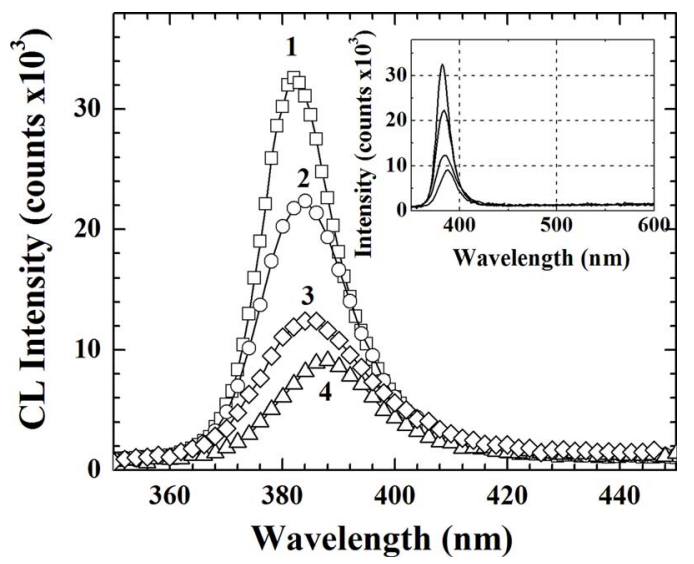

FIG. 1. NBE cathodoluminescence spectra of samples 1-4 taken at room temperature. The peaks are at $382,384,385$, and $387 \mathrm{~nm}$, respectively. Inset: broad-range CL spectra of the same samples.

be about 16.1, 19.4, 23.5, and $21.7 \mathrm{~nm}$ (corresponding to 136, 163, 196, and $178 \mathrm{meV}$ ) for samples $1,2,3$, and 4 , respectively.

The intensity of NBE luminescence was also monitored as a function of temperature. It was observed that the intensity decays with sample temperature $T$, in agreement with the following expression: ${ }^{14}$

$$
I=\frac{A}{1+B \exp \left(-E_{A} / k T\right)},
$$

where $A$ and $B$ are scaling factors, $E_{A}$ is activation energy, and $k$ is Boltzmann's constant. From Eq. (1), it can be deduced that the inverse intensity, $1 / I$, should exhibit an exponential dependence on $1 / k T$. This is shown in the inset of Fig. 2 on the example of sample 1. Note that the intensity in this and subsequent figures was normalized with respect to its room-temperature value for each of the samples. The activation energies $E_{A}$ were obtained from the slopes of Arrhenius plot shown in Fig. 2. In case of a $\left(e, A^{0}\right)$ transition, $E_{A}$ is related to the ionization energy of acceptors: the lower the value of the activation energy, the more likely is the ionization of the acceptor by a valence band electron $\left(A^{0}\right.$

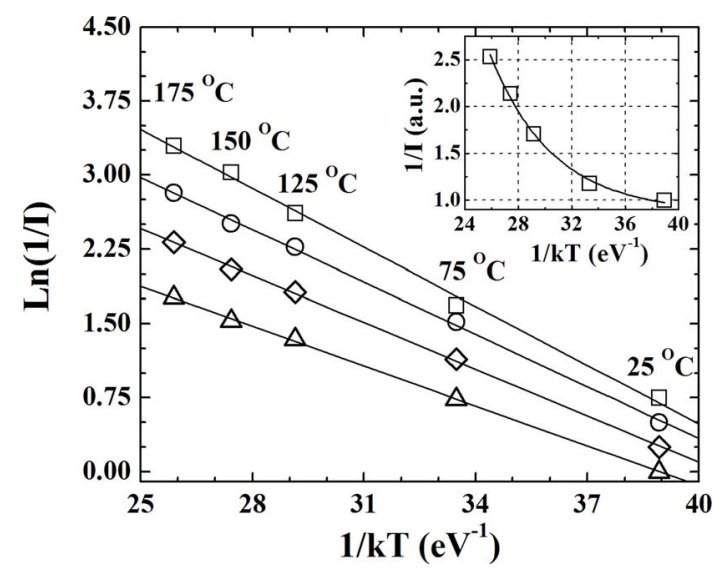

FIG. 2. Arrhenius plot showing the decay of normalized NBE luminescence intensity with increasing temperature for sample 1 (open squares), sample 2 (open circles), sample 3 (open diamonds), and sample 4 (open triangles). The linear fits (solid lines) yielded activation energies of $212 \pm 28,175 \pm 20$, $158 \pm 22$, and $135 \pm 15 \mathrm{meV}$ for samples $1,2,3$, and 4, respectively. The data were vertically offset for clarity. Inset: Exponential decrease of CL intensity for sample 1 (open squares) and the fit (solid line).

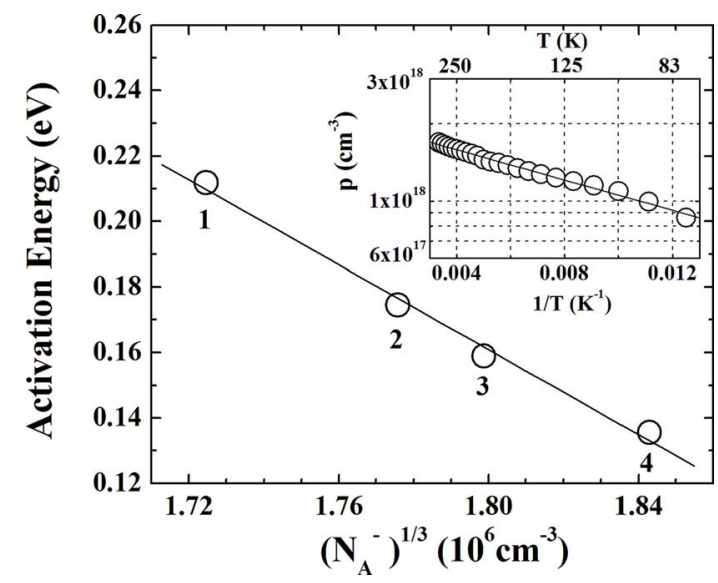

FIG. 3. Decrease of activation energy as a function of ionized acceptor concentration. Inset: Temperature dependence of hole concentration in sample 4.

$+e \rightarrow A^{-}$); since an ionized level does not participate in recombination via the $\left(e, A^{0}\right)$ route, the rate of these transitions (i.e., the intensity of the luminescence) decreases with $E_{A}$ at any given temperature. Conversely, for a constant $E_{A}$, the intensity decays with increasing temperature as more and more acceptors are ionized.

It is apparent from Fig. 2 that the activation energy shows a systematic dependence on the carrier concentration. The values of $E_{A}$ are $212 \pm 28,175 \pm 20,158 \pm 22$, and $135 \pm 15 \mathrm{meV}$ for samples $1,2,3$, and 4 , respectively. These values are in reasonable agreement with the ionization energy of an $\mathrm{Sb}_{\mathrm{Zn}}-2 \mathrm{~V}_{\mathrm{Zn}}$ complex predicted by Limpijumnong et al. to have a value of about $160 \mathrm{meV}{ }^{8}$ Furthermore, the decay of activation energy with carrier density, $p$, follows a common pattern observed previously in other semiconductors ${ }^{13,16,17}$ and is described by an equation of the type

$$
E_{A}\left(N_{A}^{-}\right)=E_{A}(0)-\alpha\left(N_{A}^{-}\right)^{1 / 3},
$$

where $N_{A}^{-}$is the concentration of ionized acceptors, $E_{A}(0)$ is the ionization energy at very low doping levels, and $\alpha$ is a constant accounting for geometrical factors as well as for the properties of the material. Figure 3 demonstrates that Eq. (2) provides a reasonable fit to the experimentally obtained activation energies under the approximation that $N_{A}^{-}-N_{D}^{+}=p$, where $N_{D}^{+}$is the density of ionized shallow donors (due to compensation, the $p$-type conductivity is determined by the difference between the concentrations of ionized donors and acceptors). The value of $\alpha$ was found to be equal to 6.4 $\times 10^{-7}$, which is comparable to that in $p$-GaN and $p$-Si. ${ }^{13,17}$ $N_{D}^{+}$can be roughly estimated from the electron concentration in undoped, $n$-type $\mathrm{ZnO}$ samples grown by the same method and is about $5 \times 10^{18} \mathrm{~cm}^{-3}$.

It should be noted that earlier PL measurements performed on sample 4 showed a consistent activation energy of $140 \mathrm{meV} .{ }^{15}$ Furthermore, temperature-dependent measurements of hole concentration in sample 4 shown in the inset of Fig. 3 also support the involvement of acceptor levels (see Ref. 6 for more details).

Although the existence of other Sb-related acceptors cannot be categorically excluded, their involvement in the temperature-induced CL intensity decay is highly unlikely. ${ }^{8}$

The phenomenon of variation of the dopant activation energy with carrier concentration in semiconductors has been 
attributed to a number of causes. Among these are the formation of the band-tail states that extend into the forbidden gap, the broadening of the acceptor band in the gap, and the reduction of binding energy due to Coulomb interaction between the holes in the valence band and the ionized acceptor states. $^{12,13,16}$

In summary, the variable-temperature cathodoluminescence studies of Sb-doped $p$-type $\mathrm{ZnO}$ allowed us to estimate the activation energy of the Sb-related acceptor in the range of $135-212 \mathrm{meV}$. The activation energy was found to be strongly dependent upon the hole concentration. While the nature of the acceptor cannot be determined conclusively, evidence suggests that it is an $\mathrm{Sb}_{\mathrm{Zn}}-2 \mathrm{~V}_{\mathrm{Zn}}$ complex proposed by Limpijumnong et al.

The work at the University of Central Florida was supported in part by the National Science Foundation (ECS 0422604) and the American Chemical Society Petroleum Research Fund (40501-AC10). The work at the University of California, Riverside was supported by DARPA/DMEA through the Center for NanoScience and Innovation for Defense (H94003-04-2-0404). The work at UF was sponsored by ARO under Grant No. DAAD19-01-1-0603, the Army Research Laboratory, NSF (DMR 0400416, DMR 0305228, and Dr. L. Hess), DOE Grant No. DE-FC26-04NT42271, and DOE Contract No. DE-AC05-00OR22725.
${ }^{1}$ F. G. Chen, Z. Z. Ye, W. Z. Xu, B. H. Zhao, L. P. Zhu, and J. G. Lv, J. Cryst. Growth 281, 458 (2005).

${ }^{2}$ Y. W. Heo, K. Ip, S. J. Pearton, and D. P. Norton, Phys. Status Solidi A 201, 1500 (2004).

${ }^{3}$ V. Vaithianathan, B. T. Lee, and S. S. Kim, J. Appl. Phys. 98, 043519 (2005).

${ }^{4}$ Y. R. Ryu, S. Zhu, D. C. Look, J. M. Wrobel, H. M. Jeong, and H. W. White, J. Cryst. Growth 216, 330 (2000).

${ }^{5}$ V. Vaithianathan, B. T. Lee, and S. S. Kim, Appl. Phys. Lett. 86, 062101 (2005).

${ }^{6}$ F. X. Xiu, Z. Yang, L. J. Mandalapu, D. T. Zhao, J. L. Liu, and W. P. Beyermann, Appl. Phys. Lett. 87, 152101 (2005).

${ }^{7}$ T. Aoki, Y. Shimizu, A. Miyake, A. Nakamura, Y. Nakanishi, and Y. Hatanaka, Phys. Status Solidi B 229, 911 (2002).

${ }^{8}$ S. Limpijumnong, S. B. Zhang, S. H. Wei, and C. H. Park, Phys. Rev. Lett. 92, 155504 (2004).

${ }^{9}$ O. Lopatiuk, L. Chernyak, A. Osinsky, and J. Q. Xie, Appl. Phys. Lett. 87, 214110 (2005).

${ }^{10}$ O. Lopatiuk, W. Burdett, L. Chernyak, K. P. Ip, Y. W. Heo, D. P. Norton, S. J. Pearton, B. Hertog, P. P. Chow, and A. Osinsky, Appl. Phys. Lett. 86, 012105 (2005).

${ }^{11}$ K. Thonke, T. Gruber, N. Teofilov, R. Schonfelder, A. Waag, and R. Sauer, Physica B 308, 945 (2001).

${ }^{12}$ M. G. Cheong, K. S. Kim, C. S. Kim, R. J. Choi, H. S. Yoon, N. W. Namgung, E. K. Suh, and H. J. Lee, Appl. Phys. Lett. 80, 1001 (2002).

${ }^{13}$ P. Kozodoy, H. L. Xing, S. P. DenBaars, U. K. Mishra, A. Saxler, R. Perrin, S. Elhamri, and W. C. Mitchel, J. Appl. Phys. 87, 1832 (2000).

${ }^{14}$ D. S. Jiang, H. Jung, and K. Ploog, J. Appl. Phys. 64, 1371 (1988).

${ }^{15}$ F. X. Xiu, Z. Yang, L. J. Mandalapu, D. T. Zhao, and J. L. Liu, Appl. Phys. Lett. 87, 252102 (2005).

${ }^{16}$ W. Gotz, R. S. Kern, C. H. Chen, H. Liu, D. A. Steigerwald, and R. M. Fletcher, Mater. Sci. Eng., B 59, 211 (1999).

${ }^{17}$ P. P. Debye and E. M. Conwell, Phys. Rev. 93, 693 (1954). 